\title{
POLLEN CARRYOVER BETWEEN SEQUENTIAL FORAGING TRIPS BY A SOLITARY BEE: IMPLICATIONS FOR DISTANT OUTCROSSING
}

\author{
James H. Cane* and Byron Love \\ USDA-ARS Pollinating Insect Research Unit, Utah State University, Logan 84322-5310
}

\begin{abstract}
Animal pollination depends on foragers moving pollen between conspecific flowers and plants. Pollinating bees often exhibit patch fidelity and frequent grooming during a foraging trip, which results in intensely localized pollen carryover. If their host's seed dispersal is likewise limited, then spatial mosaics of small genetic neighbourhoods should result. However, spatial distributions of genetic markers of seeds often reveal infrequent longdistance gene flow mediated by pollinating bees, seemingly at odds with expectations of bees' local patch fidelity and suggesting an additional mechanism at work.

A greenhouse experiment that used nesting Osmia californica bees foraging at sunflowers tested the pollination fate of any bodily pollen that lingers on females even after they discharge a pollen load at their nest. Once a provisioning female had returned to her nest, we moved the nest with her inside from a cage with male-fertile sunflowers to a cage with male-sterile sunflowers. There females quickly resumed foraging. They nearly always pollinated and set seed at the first male-sterile flowerhead that they visited, the result of fertile bodily pollen carried over from the previous foraging trip. Every visit to a second male-sterile flowerhead set additional seed.

If, as seems likely, outbound nesting females sometimes switch between host patches, then this mechanism of pollen carryover could explain occasional distant pollen-mediated gene flow events, as summarized in a graphic model. Carryover should mitigate inbreeding depression in threatened plant populations, or conversely, sometimes contaminate seed crops, with relevance for spatially isolating foundation seed fields and coexistence of GMO and conventional crops.
\end{abstract}

Keywords: Asteraceae, grooming, Megachilidae, Osmia, pollen-mediated gene flow, pollination

\section{INTRODUCTION}

Among plant-animal mutualisms, both pollination and seed dispersal involve visitors that remove and transport propagules (pollen or seeds). Pollination then has an extra step, being the subsequent receipt of pollen at a receptive stigma. Bees are the predominant pollinators in most plant communities and croplands, conferring valuable outcrossing as they move between sequential plants during a foraging trip. However, females typically move among neighbouring conspecific flowers and plants during a foraging bout (e.g. Waddington 1979; Waser 1982; Thomson \& Thomson 1989; Cresswell et al. 1995), an outcome of floral constancy and the reproductive advantages of minimizing travel time and energy spent. As a result, a foraging bee tends to thoroughly work a rewarding patch (or tree), moving only short distances between flowers (Waddington 1979; Thomson \& Thomson 1989; Rasmussen \& Brodsgaard 1992). Pollen flow should follow this foraging pattern, given the rapid decay in pollen carried over from previously visited flowers (e.g. Cresswell et al. 2002). The few available studies (all using bumble bees) do show that pollen transferred to a bee's body is quickly lost from the pollination pool after just a few subsequent flower visits (Thomson et al. 1986; Waser 1988; Thomson \&

Received 2I August 2018, accepted 29 August 2018

*Corresponding author: jim.cane2@gmail.com
Thomson 1989; Cresswell et al. 2002; Castellanos et al. 2003). To better appreciate the significance of a new pollen carryover mechanism, we first review the extent to which bees' foraging and transport traits constrain pollen-mediated gene flow to distances that are far short of bees' estimated flight ranges. We then present experimental evidence for a new mechanism of pollen carryover by bees.

Pollen carryover curves have been measured mostly for foraging bumble bees, for which carryover is often truncated or foreshortened by the bees' regular grooming and pollen packing while in a patch. Both actions further limit the spatial extent of gene flow by foragers. Periodic grooming largely terminates reproductive chances of most pollen (Thomson I986; Holmquist et al. 2012), as a forager periodically sweeps loose surface pollen from her body to pack and transport it back to her nest. Residual dry pollen only lingers on bodily surfaces that cannot be groomed (e.g. Tepedino et al. I999). Pollen in such "safe sites" nonetheless becomes buried by more recently deposited pollen, again limiting carryover (Thomson 1986). In addition, bumble bees, honey bees, and some other bees moisten groomed pollen with nectar while packing it on their hind legs, effectively terminating its ability to germinate (Parker et al. 2015). Most other non-parasitic bee taxa transport pollen dry, where it remains viable and sometimes well-placed for further pollination (e.g. abdominal venters of megachilids visiting Asteraceae flowers; Cane 2017). Collectively, these factors constrain pollen-mediated gene flow by bees. The genetic neighbourhoods resulting from 
pollen flow can extend several hundred meters for widelyspaced tropical rainforest trees pollinated by big-bodied, vagile bees (Dick et al. 2003; Ward et al. 2005; Jha \& Dick 2010). More commonly, these genetic neighbourhoods are small, spanning a few meters for forbs (Rasmussen \& Brodsgaard 1992; Fenster et al. 2003; Otero-Arnaiz et al. 2005) and row crops (St. Armand et al. 2000; Van Deynze et al. 2005).

Wherever pollen-mediated gene flow has been spatially well-sampled, though, population geneticists report right skewed leptokurtic distributions with a long tail, akin to rare but distant seed dispersal events (Clark et al. 200I). That tail represents distant albeit infrequent pollen flow events mediated by pollinators (Bradner et al. 1965; Rieger et al. 2002; Van Deynze et al. 2005). Distant gene flow can be problematic for agricultural seed production (Bradner et al. 1965), where varietal purity is paramount (Van Deynze et al. 2008; Greene et al. 20I5). Conversely, rare plant conservation often benefits from distant outcrossing that can counter genetic drift and inbreeding depression (e.g. Paschke et al. 2002). These practical ramifications compel us to understand the mechanisms contributing to infrequent but distant pollen flow by foraging bees.

The potential significance of a new pollen carryover mechanism becomes apparent from a review of the spatial realities of bee foraging patterns and interfloral carryover during a foraging trip. Females range out to forage from a central nest, so their potential pollen flow distance is bounded by their flight range. Even for smaller solitary bees, maximum foraging distances ("M" in Fig. I) are often a $\mathrm{km}$ or more (Zurbuchen et al. 20I0b). However, bees' maximum flight ranges greatly overestimate the spatial scales of their realized contribution to pollen-mediated gene flow. For solitary bees, those that must forage distantly forego some progeny production (Zurbuchen et al. 2010a). Unique to honey bees, flight distances and directions are measured by decoding forager's waggle dances in the hive (Seeley I995). Outbound foragers sometimes fly far (e.g. 5-9 kms) to reach distant rewarding patches, but only when nearer patches are wanting (Beekman \& Ratnieks 2000). To minimize time and energy costs, they more typically forage much closer to home, ranging out $500 \mathrm{~m}-3 \mathrm{~km}$ (reviewed in Seeley 1995). Hence, most pollination by solitary and social bees is much closer to their nests than their maximum foraging ranges would imply ( $\mathrm{M}$ vs. $\mathrm{R}$ in Fig. I).

Even these reported radial foraging distances flown by bees greatly exceed the spatial scale of their conferred pollenmediated gene flow. Although bees foraging in crop fields and orchards often range out hundreds of meters, measured pollen-mediated gene flow rarely exceeds a few meters (Handel 1983; St. Armand et al. 2000; Van Deynze et al. 2005). This highly localized pollen travel ( $G_{1}$ in Fig. I) results because bees apparently fly out and over the intervening landscape, then drop into a rewarding patch (or part of an agricultural field) to forage intensively among neighbouring, often conspecific flowers (L in Fig. I). Studies supporting this contention have been limited to select social bees, as outbound flights of free-flying solitary species cannot be visually followed or experimentally manipulated. For honey bees, outbound foragers that were recruited to distant scented nectar feeders rarely investigated intervening scent stations placed along their route (Fig. 9I in von Frisch 1967). Extrapolating this discovery to scattered flower patches, recruited honey bees can be expected to fly past intervening flowers en route to the target floral patch. Unlike honey bees, bumble bees (and all solitary bees) forage independently without recruitment. Although bumble bees have been implicated in moving pollen up to $400 \mathrm{~m}$ (Schulke \& Waser 200I), watching them fly between more distant floral patches generally fails. Only through use of harmonic radar has this limitation been remedied. Because only a big bee can tote the antenna mast, only the complete foraging trips of tagged bumble bees flying across extensive open landscapes have so far been tracked (Osborne et al. 1999; Woodgate et al. 2016). All but two similarly rigged large carpenter bees ( $X_{y}$ locopa) quickly lost their transceivers (Pasquet et al. 2008). Outbound experienced bumble bee foragers were seen to fly directly to distant $(>200 \mathrm{~m})$ small floral patches during "exploitation" flights (Woodgate et al. 2016); these foragers "were not searching for food en route" (Osborne et al. 1999), just as von Frisch reported for honey bees. These direct, non-stop outbound and return flights from nest to foraging patch largely explain why, despite these bees' extensive foraging ranges, their pollen-mediated gene flow is intensely localized, resulting in surprisingly small genetic neighbourhoods.

However, there remain the regular but rare distant pollen flow events that yield distant outcrossing. For the non-social
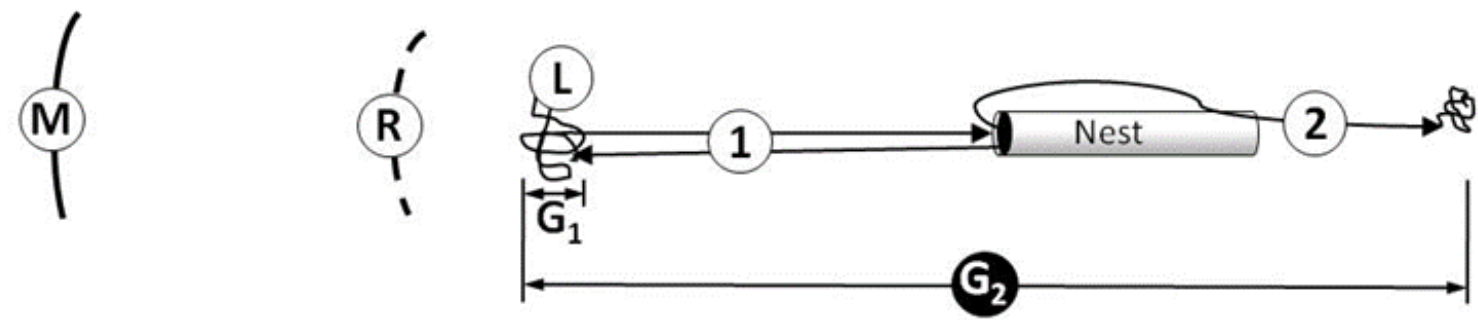

FIGURE I. Graphic model depicting the spatial patterns of a bee's home range, two foraging trips and resulting pollen-mediated gene flow (not to scale). Labels are: $\mathrm{M}=$ maximum flight range, $\mathrm{R}=$ realized home foraging range, $\mathrm{L}=$ localized foraging bout in a flower patch, I \& $2=$ sequential foraging trips by nesting bee, $\mathrm{G}_{\mathrm{I}}=$ small genetic neighbourhood resulting from patch fidelity on one foraging trip, $\mathrm{G}_{2}=$ pollen flow distance resulting from carryover into a sequential foraging trip. 
bee Megachile rotundata, which is managed to pollinate alfalfa seed fields, St. Armand et al. (2000) found very short distances $(<4 \mathrm{~m})$ for most pollen-mediated gene flow. However, he and others (Bradner et al. 1965) also did find infrequent instances of distant travel by alfalfa pollen markers (out to $1000 \mathrm{~m}$ ). Similarly, among wild patches of Cucurbita foetidissima pollinated by specialist Peponapis bees, most pollen-mediated gene flow was within patches, but $7 \%$ was between them (to $500 \mathrm{~m}$; Kohn \& Casper 1992). These instances may simply represent rare departures from these bees' usual behaviour during a foraging bout. Alternatively, long-distance pollen flow could represent a different mechanism, namely the carryover of bodily pollen from the previous foraging trip.

Consistent with this carryover mechanism, experiments with sequential foraging trips by honey bees in crop monocultures showed that departing foragers carry some viable pollen on their bodies (Hatjina et al. 1999) that continues to pollinate flowers (Free \& Durrant I966). In the latter study, apple pollen on bodies of outbound bees was acquired either on their previous foraging trip (carryover) or when foragers jostled against each other in the crowded hive. Pollen transfer during forager jostling was implied by experiments of DeGrandi-Hoffman et al. (I986), wherein outbound foragers picked up pollen from dead hive mates pinned at the hive entrance. In contrast, using more direct experiments, investigators who marked and released newly emerged, pollen-free workers into hives placed adjacent to cotton fields (Loper \& DeGrandi-Hoffman 1994) found that, after $6 \mathrm{~h}$, the marked hive bees had only acquired a few dozen pollen grains from returning foragers, none of it cotton. For social bees, it seems impossible to discern individual pollen carryover from pollen transfer during nestmate jostling. Most bees are not social but solitary, however, and so of course they have no nestmates to jostle. For a solitary bee, then, any bodily pollen on an outbound female must stem from her inability to completely groom and remove it while in her nest. This mechanism was shown for the solitary bee Osmia corniffons, whose outbound females retained $10 \%$ of their bodily loads after off-loading at their nests (Matsumoto et al. 2009). However, its contribution to pollination was not tested.

If leftover pollen on bodies of outbound bees is to contribute to distant gene flow of their floral hosts, then on sequential foraging bouts, bees must sometimes visit a new floral patch ("2" in Fig. I). Unfortunately, patch switching by free-flying non-social bees has proven logistically impossible to document at spatial scales of the field. However, freely foraging bumble bees tracked using harmonic radar did occasionally switch patches (Osborne et al. 1999; Woodgate et al. 2016). In each case, foragers switched patches on a subsequent outbound flight, not during a given trip. The combination of bodily pollen carryover from the previous foraging trip and switching flowering patches on some subsequent foraging trips could together account for the occasional long-distance gene flow events observed using genetic markers of bee-pollinated plants ("G2" in Fig. I). The objective of this study was to directly and experimentally test half of this hypothetical mechanism, namely that pollen being carried-over from a solitary bee's previous foraging trip can contribute to subsequent pollination and seed set.

\section{MATERIALS AND METHODS}

\section{Study organisms}

The experiment required a portable population of a solitary bee that could be induced to forage and nest in confinement using a suitable pollen host that could be brought to bloom concurrently with bee nesting. For this purpose, we chose a solitary cavity-nesting bee, Osmia californica Cresson, which is an Asteraceae specialist (Cripps \& Rust 1989). These bees were progeny of a local population being propagated outdoors on their native perennial floral host, Balsamorhiza sagittata (Cane 20II). They readily nest in large cages and accept sunflowers as a pollen host (Cane 2017).

For a practical annual Asteraceae host bearing a malesterile trait, we grew dwarfed, determinant commercial sunflower cultivars (Helianthus annuus L.) that are marketed for the cut-flower trade. The pollen-bearing variety was 'Sunspot'. The recipient male-sterile, pollen-less variety was 'Solita' (Johnny's Selected Seeds, Winslow, Maine). Each plant of both cultivars concurrently produced a single, similarlooking large yellow flowerhead. Experiments took place in an earth-floored glasshouse into which we sowed separate patches of the two sunflower cultivars, one within each of two neighbouring partitions $(3.4 \times 6.2 \times 2.5 \mathrm{~m})$ of a large hanging net cage. For a more familiar vocabulary, we shall refer to the sunflower's capitulum as a flowerhead, its individual flowers as florets, and its achenes as seeds.

\section{Experiments}

Cocoons of a wintered population of $O$. californica were incubated for a few days in early May so that adults were active during their local flight season. Each newly-emerged female was briefly chilled and given a unique thoracic paint mark. Females plus five males were then released into the cage with the pollen-bearing variety; 17 females commenced to forage and nest. Both cages were given a weathered, 49-hole drilled wooden nesting block with new paper straw inserts. Both nest blocks were placed in matching positions and orientations within their respective cages. Bees were monitored for the onset of nest cell provisioning, checked by viewing the nest's interior using an otoscope. Our intent was to create two visually similar nesting/foraging arenas between which we could individually shuttle actively provisioning bees while in their nesting straws, all without disturbing their foraging routines.

To shuttle bees between arenas, we awaited the return of a pollen-laden female to her nesting block. A female first walks into her nest head-first to disgorge her nectar load, then backs out, reverses direction on the nest block face, and backs into the straw to groom off her pollen load onto the growing provision mass. At that moment, we corked the front of her nesting straw, withdrew the occupied straw, and while holding it horizontally, we gingerly walked it to the nesting block in the adjoining cage with the pollen-less sunflowers. The straw was slipped into the same relative position in the provided block and uncorked to await the female's emergence. Thus, all females emerged having first groomed away their pollen loads at their nest, which we confirmed visually. With this design, seed set at the pollen-less variety would have to result from 
properly positioned loose pollen on a bee's body that was acquired from the pollen-bearing variety during the previous foraging trip.

Foraging females walked the flowerheads in arcs, following the narrow circle of newly-opened florets. We marked each female's landing and departure points with map pins on a pollen-less flowerhead while drawing her route and direction of travel on paper. After her departure, we enclosed the visited flowerhead in a paper bag for the rest of the experiment. We thereafter measured the length of arc that she walked so we could both estimate pollination efficacy per unit foraging effort (seeds per $\mathrm{cm}$ walked) as well as detect if there were declining seed returns as a visit progressed. It is impossible to know which individual florets females touched as they walked the ring of receptive florets. Any visit to a second flowerhead was similarly recorded. Each female was then removed, placed back in her nesting straw, and returned to the nest block in the cage with the pollen-bearing sunflowers. Each female was used only once.

Mature seeds (plump achenes) were harvested from individual flowerheads. The seeds along a bee's arcuate path around each flowerhead (marked by the pins) were extracted, collected and counted in sequential quarter arcs in the direction that the bee had walked. Any shorter remaining arcs were recorded separately. Achenes were rubbed free and sorted into two distinct classes: flat and flexible, or plump and hard (inset Fig. 4). X-radiographs revealed that only the plump hard achenes contained endosperm, a difference that we confirmed by sample dissection.

\section{Statistics}

The comparative likelihood of a female's pollen carryover resulting in pollination was tested using a simple $2 \times 2$ contingency table and logistic regression (Allison 2012), comparing the frequency of visits that yielded filled achenes in the bee's walking path versus any filled achenes of neighbouring florets untouched by bees. A hypothesis of diminishing seed returns was tested by paired t-tests on square roots of counts of seeds in two ways, comparing: I) yields from the first $1 / 4$ arc walked with the $3^{\text {rd }}$ arc walked on the first flowerhead visited, and 2 ) yields at the first flowerhead versus the second one visited. Seed yields per flowerhead were regressed on bees' walking distances (after square root transformation to satisfy normality; SigmaPlot, Systat Software Inc., San Jose, California).

\section{RESULTS}

Foraging and nesting behaviours appeared to be normal despite confinement to large cages in a glasshouse environment. After several days of orientation and feeding, females commenced nesting. They actively collected pollen loads, using rapid dorso-ventral drumming of their abdominal scopa (pollen-brush) against the day's ring of presenting florets on the flowerhead (Cane 2016). In the experiment, of the 17 females emerging from their translocated nests, I5 individuals flew directly to a male-sterile flowerhead to resume foraging, apparently undisturbed by their transfer. The other two flew to the cage walls and were not used. Most females lingered 30 secs or less before emerging, which combined with our straw removal and walking times between cages, falls within the norms for time female $O$. lignaria spent removing pollen (30 secs) and resting (I5-60 secs) in glass nest tubes (Phillips \& Klostermeyer I978).

Transferred females visited 24 of the available flowerheads of the pollen-less sunflowers, walking a total of $3.4 \mathrm{~m}$ along the day's ring of presenting florets. Twelve females walked at least $3 / 4$ of an arc (path $\mathrm{I} 4 \pm 8 \mathrm{~cm}$ long, range $2-28 \mathrm{~cm}$ ) while following the ring of receptive florets on a given flowerhead; seven females walked a complete circuit. Nine females visited a second flowerhead. All females took nectar; some were seen trying to actively collect pollen from pollen-less flowerheads by abdominal drumming (Cane 2017), but of course the florets bore no pollen. Each female with her nest was returned to the nesting cage, where they all resumed foraging and provisioning.

Bodily pollen carried over from the previous foraging trip frequently yielded filled achenes at male-sterile flowerheads (2I of 24 visits), whereas filled achenes never formed at untouched florets or from two of the three shortest walks (2$3 \mathrm{~cm}$; Fig. 2). Visitation and carryover significantly improved the likelihood of seed set $(\mathrm{G}=20.5, P \leq 0.000 \mathrm{I})$. Overall, pollen carryover yielded 534 plump achenes (mean $=22 \pm$ 36 achenes per flowerhead, median 7). Just three of the 24 visits accounted for $315(59 \%)$ of the total set of plump achenes (Fig. 2). Converted to a bee's walking distance on a flowerhead, seed set averaged $1.7 \pm 2$ seeds per $\mathrm{cm}$ walked (median 0.8, range 0-6.4). However, distance walked per flowerhead $(2-28 \mathrm{~cm})$ did not predict seed yield (0-I40 seeds $\left.t^{2}=0.05, P>0.3\right)$ although, of course, the shortest walks could not yield much seed (Fig. 2).

Our hypothesis of diminishing returns -- that progressively less seed would result as a female continued to forage at male sterile sunflowers -- gained only partial support from our small data set. At the first flowerhead visited, some seeds resulted from every final $1 / 4$ arc for the five bees that walked a complete circuit, so clearly bodily pollen remained. Comparing seed set along the $\mathrm{I}^{\text {st }}$ and $3^{\text {rd }} \mathrm{I} / 4$ arcs walked by ten

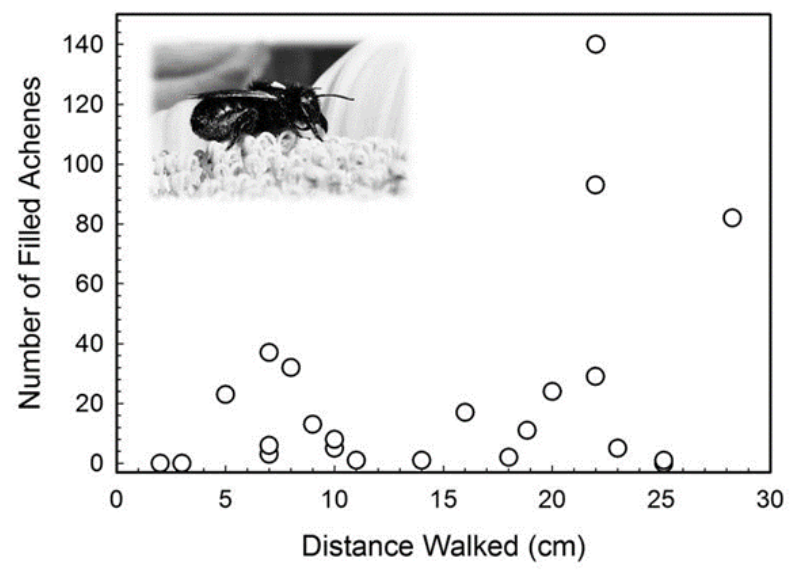

FIGURE 2. Scatterplot of plump achenes resulting for the distance walked by each transferred female $O$. californica visiting one of 24 male-sterile sunflower flowerheads (second visited flowerheads plotted independently). Inset Female $O$. californica transporting 'Sunspot' sunflower pollen in her ventral abdominal scopa (pollenbrush). 


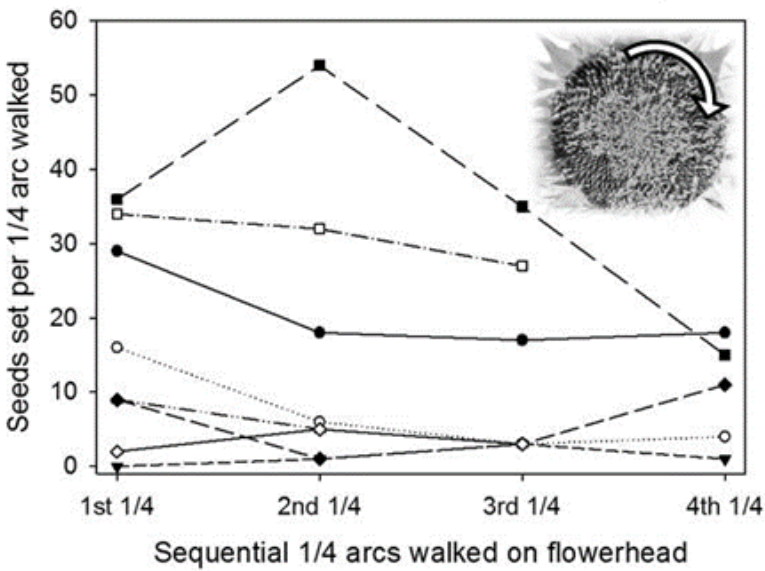

FIGURE 3. Changes in rates of achenes set by each female $O$. californica as she visited progressive $1 / 4$ arcs of receptive flowers on a single flowerhead. Only included are those eight females that walked at least $3 / 4$ of an arc and set five or more seeds. Inset Flowerhead with a broad ring of black, matured seeds resulting from a single Osmia visit. First $1 / 4$ arc of travel marked.

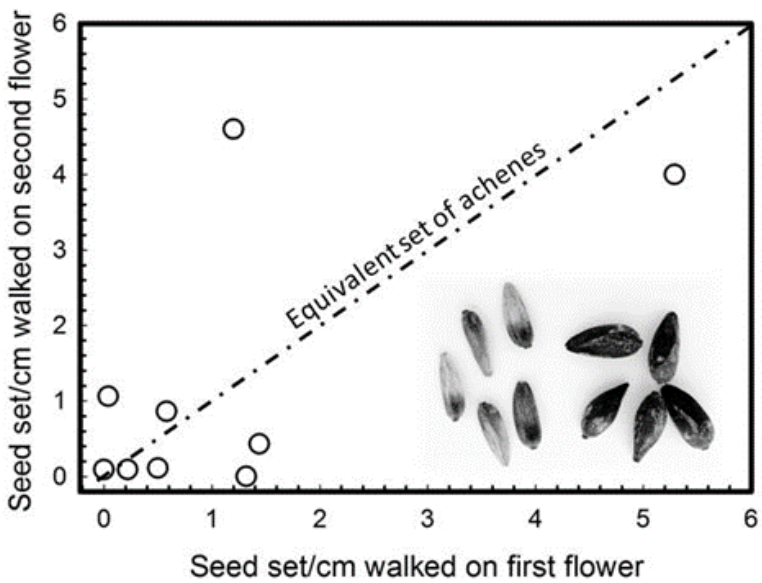

FIGURE 4. Scatterplot for the numbers of filled achenes set per $\mathrm{cm}$ walked by the nine female $O$. californica that visited two flowerheads sequentially, comparing the first visited flowerhead $(x-$ axis) with the second (y-axis). Points below the dashed line indicate diminishing returns at the second flower. Inset Image comparing plump achenes filled with endosperm that were counted in these experiments (right) versus thin, flexible empty achenes.

females (Fig. 3), the first $1 / 4$-arcs walked yielded more seed overall (sum 135 vs. 97 seeds) and for the six most effective pollinators (sum 22I seeds). However, for 4 of the 9 visits to a second flowerhead (Fig. 4), seed set per $\mathrm{cm}$ walked on the second flowerhead exceeded that of the first. Thus, pollination continued for two flowerheads, but the order of flowerhead visitation did not predict resulting seed set (one-tailed $t=1.9$, $P>0.4, N=9)$.

\section{DISCUSSION}

The common observation that foraging solitary bees show local patch fidelity seems at odds with the infrequent but distant pollen-mediated gene flow revealed by genetic markers of some bee-pollinated flowering species. This paradox is readily reconciled if bodily pollen is carried over between sequential foraging trips and females occasionally exit their nest to forage in a different patch (Fig. I). Nesting female $O$. californica apparently departed their nests with pollen from their preceding foraging trip $(\mathrm{s})$, as we found that substantial seed resulted from their visits to male-sterile sunflowers, this despite the females having first groomed and deposited their pollen loads at their nests. Some seed resulted from most $(89 \%)$ visitation bouts owing to this mechanism,

Just 3 of the 24 visits set $59 \%$ of the total seed in the experiment, a seemingly rare event. However, female solitary bees make many such foraging flights in a day. For instance, both $O$. californica and $O$. montana require 30 pollen trips to provision each nest cell (Torchio I989). They provision one, sometimes two nest cells every day for several weeks, tempos matched by several other cavity-nesting Osmia (e.g. Maeta 1978; Phillips \& Klostermeyer 1978; Frohlich \& Tepedino 1986; Bosch 1994; Goodell 2003). For ground-nesting species, counts of provisioning trips per nest cell are difficult to know with confidence (as cell completion is hidden from the observer), but they also are thought to average several dozen flights per day (Neff 2008) during several weeks of nesting. Thus, a typical adult female solitary bee flies 200-400 foraging trips in her lifetime, affording 200-400 opportunities for pollen carryover between sequential foraging trips. Extrapolating from our study, I3\% (3/24) of these trips should yield substantial pollination via pollen carried over from the preceding foraging trip, or an estimated 25-50 substantial carry-over events during each female's lifetime. If just a few of these trips involve outgoing bees changing patches from the previous foraging trip, then there would be ample opportunity for the occasional distant pollen-mediated gene flow events that have been revealed by genetic studies.

Some protocols and choices necessary to this experiment undoubtedly influenced carryover. First, we truncated foraging sequences after the second flowerhead visited, so as to reserve enough flowerheads for other bees' visits. Later, when processing mature achenes, we found little evidence of diminishing carryover pollination during these first two floral visits (Fig. 4), so pollination by carry-over pollen likely would have continued to three or more flowerheads. Hence, we surely underestimated the total possible carryover of pollen acquired during the previous foraging trip. Conversely, because the target sunflower variety lacked pollen (male-sterile), bees visiting these flowerheads did not groom (although some did drum as if there was pollen to collect). Grooming has been shown to sharply curtail -- but not eliminate -- further pollen carry-over by bumble bees (Thomson 1986; Thomson \& Thomson 1989; Holmquist et al. 2012). The availability and exposure of pollen carried over from the previous foraging trip thus may be prolonged for bees visiting male-sterile (or monoecious or dioecious) flowers relative to more typical hermaphroditic flowers. However, as a guild of foraging bees daily depletes their host's standing crop of pollen, there should be a time each day when most flowers have been depleted but a small fraction are not yet visited. For instance, given a purely Poisson process, once the average flowerhead has been visited a third time, there would remain 5\% unvisited flowerheads. At that time, foragers departing a pollen-bearing flowerhead encounter mostly pollen-less flowers, as we used here. Lastly, for females foraging at pollen-bearing flowerheads, pollen acquired earlier can be buried under newly acquired pollen, at 
least until the bee grooms. In our system, bees foraging at male-sterile sunflowers had no occasion to groom.

The attributes of the bees and flowers used in this experiment do seem ideal for pollen carryover to occur. The 3,000+ species of non-parasitic Megachilidae bees (like Osmia) all transport pollen dry in their abdominal pollenbrush (scopa). There it remains in play for pollination, especially for flowers like most of the huge plant family Asteraceae ( $>20,000$ species) or others that instead produce panicles or umbels over which the foraging megachilid bee simply walks, often while drumming their scopa against the pollen-bearing surface (Cane 20I7). In contrast with megachilids, all social bees and the other solitary bees transport pollen on their hind legs, some of them (bumble bees, stingless bees, honey bees) moistening the pollen with nectar to form a pellet. Every time these bees groom and pack pollen onto their hind legs, it is removed from circulation, which for bumble bees has been shown to hasten attenuation of pollen carryover during a foraging trip (Thomson I986), and so probably from a prior foraging trip too. Many other flowering species, however, place and pick up pollen on bodily surfaces that bees have difficulty grooming (e.g. thoracic dorsum, proboscidial fossa, or between their leg bases). For such flowers, just where and how these bees groom and transport pollen are immaterial. Characterizing the magnitude of pollen carryover during sequential foraging flights by bees either receiving pollen placed in these "safe" sites (e.g. pollen deposited on a bee's thoracic dorsum by Penstemon flowers) (Tepedino et al. 1999) or transporting pollen in different scopal placements (e.g. hind leg) would help for interpreting the generality of the phenomenon found here with Osmia bees visiting sunflowers.

Pollen carryover to different floral patches might also be invoked for pollen residing overnight on the body of a female sleeping in her nest, since a forager's last and first foraging trips of sequential days probably target different patches of bloom. However, given the likely humid conditions within a nest (near saturation for a ground-nester; Cane, unpubl.), pollen of many flowering species held overnight would be expected to hydrate and expire by morning (Bassani et al. 1994). For this same reason, the minority of species that shed hydrated pollen (e.g. Cucurbita) have consistently short-lived pollen (Franchi et al. 20II). It is surprising, then, that Matsumoto et al. (2009) clearly demonstrated that apple pollen on bodies of cavity-nesting $O$. cornifrons remained viable for 12 days. The reproductive value of bodily pollen carried over into subsequent foraging days should be strongly influenced by intra-nest humidities and pollen species, and so will require further experiment.

Interestingly, gene flow promoted by this pollen carryover mechanism is not diminished by a bees' localized foraging behaviour or patch fidelity during a foraging trip (Fig. I). Moreover, it can multiply the effect of flight distance. For example, a bee that switches from a small patch 300 m east of its nest to one $200 \mathrm{~m}$ west of its nest will effectively move pollen $1 / 2 \mathrm{~km}$, more than either foraging distance and far further than the short flights the female made between flowers while foraging in either floral patch (distance $G_{2}$ in Fig. I). Actual gene flow frequencies should be functions of how often outbound foragers switch floral patches, the vector angle between patches, and the distances from the nest to each patch. In our experiment, only a minority of carry-over events set substantial seed, which was not related to either distance walked or flowerhead order. Collectively, these variables would result in sporadic distant gene flow events. This expectation accords with the data for distant gene flow in large-scale crop pollination studies, which do not fit an exponential decay function for the more distant gene flow events (e.g. Rieger et al. 2002).

This inter-trip mechanism of pollen carryover should contribute to agricultural yields, such as between rows of selfincompatible crops (e.g. almond; Bosch \& Blas I994) or into rows of male-sterile lines for hybrid seed production (e.g. sunflower; Parker \& Frohlich 1983). It may also explain pollination of bee-pollinated rainforest trees. These trees are often widely scattered, self-incompatible mass bloomers (Ward et al. 2005) such as the Brazil nut (Bertholletia excelsa). This valuable Amazonian tree is largely selfincompatible; most of its seeds result from outcrossing (O'Malley et al. 1988). Its complex flowers are visited by large female non-social bees (Cavalcante et al. 2012) whose intertree movements are essential to its pollination and subsequent yield of harvested seeds.

The primary remaining question centres on the relative probability that bees switch between distant floral patches (or rows or trees) during a given foraging trip versus a subsequent foraging trip. The answer requires knowing the immediate travel histories of uniquely marked foragers seen flying into a patch, distinguishing between direct arrivals from another patch versus arrivals preceded by a nest visit, all over realistic distances (hundreds of meters). Observing and distinguishing these events have thus far eluded researchers but for the use of harmonic radar tracking of bumble bees. The second, more recent radar study with bumble bees (Woodgate et al. 2016) has revealed yet another mechanism - early, wide-ranging exploratory flights by young inexperienced foragers -- that also could result in some long-distance gene flow events between patches. Since all bees must learn to navigate within their home range to efficiently choose foraging patches (or a nesting site), it may be that such investigative young bees also confer infrequent, distant pollen flow. However, their possible contribution to pollination is not yet known. The mechanism of pollen-carryover between foraging trips by $O$. californica bees is shown here to regularly yield sunflower seed, sometimes abundantly. This mechanism reconciles the typical patch fidelity of bees during a foraging trip (Woodgate et al. 2016) and the rare but regular pollen-mediated gene flow events that occur over much greater distances, as revealed by genetic markers.

\section{ACKNOWLEDGEMENTS}

Devon Picklum contributed practical advice and later plant care in the greenhouse and in bee marking. Braden Jenkins helped follow foraging bees, and later, cleaned and sorted achenes. Jack Neff, Rebecca Irwin, T'ai Roulston and several anonymous reviewers all improved the manuscript.

\section{Authors' Contribution}

$\mathrm{JC}$ and BL conceived the ideas and designed methodology and collected the data; BL grew and maintained plantings and bees; JC 
analysed the data and wrote the manuscript. Both authors contributed critically to the drafts and gave final approval for publication.

\section{REFERENCES}

Allison PD (2012) Logistic regression using SAS: Theory and application. SAS Institute, Cary, North Carolina USA.

Bassani M, Pacini E, Franchi GG (I994) Humidity stress responses in pollen of anemophilous and entomophilous species. Grana 33:I46-I50

Beekman M, Ratnieks F (2000) Long-range foraging by the honeybee, Apis mellifera L. Functional Ecology I4:490-496.

Bosch J (1994) The nesting behaviour of the mason bee Osmia cornuta (Latr.) with special reference to its pollinating potential (Hymenoptera, Megachilidae). Apidologie 25:84-93.

Bosch J, Blas M (1994) Foraging behaviour and pollination efficiency of Osmia cornuta and Apis mellifera on almond (Hymenoptera, Megachilidae and Apidae). Applied Entomology and Zoology 29:I-9.

Bradner NR, Frakes RV, Stephen WP (1965) Effects of bee species and isolation distance on possible varietal contamination in alfalfa. Agronomy Journal 57:247-248.

Cane JH (201I) Specialist Osmia bees forage indiscriminately among hybridizing Balsamorhiza floral hosts. Oecologia 167:107II6.

Cane JH (2017) Specialist bees collect Asteraceae pollen by distinctive abdominal drumming (Osmia) or tapping (Melissodes, Svastra). Arthropod-Plant Interactions II:257-26I.

Castellanos MC, Wilson P, Thomson JD (2003) Pollen transfer by hummingbirds and bumblebees, and the divergence of pollination modes in Penstemon. Evolution 57:2742-2752.

Cavalcante MC, Oliveira FF, Maues MM, Freitas BM (2012) Pollination requirements and the foraging behaviour of potential pollinators of cultivated Brazil Nut (Bertholletia excelsa Bonpl.) trees in central Amazon rainforest. Psyche 20I2:I-9.

Clark JS, Lewis M, Horvath L (200I) Invasion by extremes: population spread with variation in dispersal and reproduction. The American Naturalist I57:537-554.

Cresswell JE, Bassom AP, Bell SA, Collins SJ, Kelly TB (I995) Predicted pollen dispersal by honey-bees and three species of bumble-bees foraging on oil-seed rape: a comparison of three models. Functional Ecology 9:829-84I.

Cresswell JE, Osborne JL, Bell SA (2002) A model of pollinatormediated gene flow between plant populations with numerical solutions for bumblebees pollinating oilseed rape. Oikos 98:375384.

Cripps C, Rust RW (1989) Pollen preferences of seven Osmia species (Hymenoptera: Megachilidae). Environmental Entomology I8:133-I38.

DeGrandi-Hoffman G, Hoopingarner R, Klomparens K (I986) Influence of honey bee (Hymenoptera: Apidae) in-hive pollen transfer on cross-pollination and fruit set in apple. Environmental Entomology 15:723-725.

Dick CW, Etchelecu G, Austerlitz F (2003) Pollen dispersal of tropical trees (Dinizia excelsa: Fabaceae) by native insects and African honeybees in pristine and fragmented Amazonian rainforest. Molecular Ecology 12:753-764.

Fenster CB, Vekemans X, Hardy OJ (2003) Quantifying gene flow from spatial genetic structure data in a metapopulation of Chamaecrista fasciculata (Leguminosae). Evolution 57:995-1007.

Franchi GG, Piotto B, Nepi M, Baskin CC, Baskin JM, Pacini E (20II) Pollen and seed desiccation tolerance in relation to degree of developmental arrest, dispersal, and survival. Journal of Experimental Botany 62:5267-528I.

Free JB, Durrant AJ (1966) The transport of pollen by honeybees from one foraging trip to the next. Journal of Horticultural Science 4I:87-89.

Frohlich DR, Tepedino VJ (1986) Sex ratio, parental investment, and interparent variability in nesting success in a solitary bee. Evolution 40:I42-I5I.

Goodell K (2003) Food availability affects Osmia pumila (Hymenoptera: Megachilidae) foraging, reproduction, and brood parasitism. Oecologia I34:5I8-527.

Greene SL, Kesoju SR, Martin RC, Kramer M (2015) Occurrence of transgenic feral alfalfa (Medicago sativa subsp. sativa L.) in alfalfa seed production areas in the United States. Plos One I0:e0I43296.

Handel SN (1983) Contrasting gene flow patterns and genetic subdivision in adjacent populations of Cucumis sativus (Cucurbitaceae). Evolution 37:760-77I.

Hatjina F, Free JB, Paxton RJ (I999) Hive-entrance pollen transfer devices to increase the cross-pollination potential of honey bees. II. Examination of three materials and pollen viability. Journal of Apicultural Research 38:3-9.

Holmquist K, Mitchell RJ, Karron JD (2012) Influence of pollinator grooming on pollen-mediated gene dispersal in Mimulus ringens (Phrymaceae). Plant Species Biology 27:77-85.

Jha S, Dick CW (2010) Native bees mediate long-distance pollen dispersal in a shade coffee landscape mosaic. Proceedings of the National Academy of Sciences 107:13760-I3764.

Kohn JR, Casper BB (1992) Pollen-mediated gene flow in Cucurbita foetidissima (Cucurbitaceae). American Journal of Botany 79:5762.

Loper GM, DeGrandi-Hoffman G (1994) Does in-hive pollen transfer by honey bees contribute to cross-pollination and seed set in hybrid cotton? Apidologie 25:94-102.

Maeta Y (1978) Comparative studies on the biology of the bees of the genus Osmia of Japan, with special reference to their managements for pollinations of crops (Hymenoptera: Megachilidae). Bulletin of the Tohoku National Agricultural Experiment Station 57:195-209.

Matsumoto S, Abe A, Maejima T (2009) Foraging behaviour of Osmia cornifrons in an apple orchard. Scientia Horticulturae I2I:73-79.

Neff JL (2008) Components of nest provisioning behaviour in solitary bees (Hymenoptera : Apoidea). Apidologie 39:30-45.

O'Malley DM, Buckley DP, Prance GT, Bawa KS (1988) Genetics of Brazil nut (Bertholletia excelsa Humb. \& Bonpl.: Lecythidaceae). 2. Mating system. Theoretical and Applied Genetics 76:929-932.

Osborne JL, Clark SJ, Morris RJ, Williams IH, Riley JR, Smith AD, Reynolds DR, Edwards AS (1999) A landscape-scale study of bumble bee foraging range and constancy, using harmonic radar. Journal of Applied Ecology 36:519-533.

Otero-Arnaiz A, Casas A, Hamrick JL (2005) Direct and indirect estimates of gene flow among wild and managed populations of Polaskia chichipe, an endemic columnar cactus in Central Mexico. Molecular Ecology I4:4313-4322.

Parker AJ, Tran JL, Ison JL, Bai JD, Weis AE, Thomson JD (2015) Pollen packing affects the function of pollen on corbiculate bees but not non-corbiculate bees. Arthropod-Plant Interactions 9:197203.

Parker FD, Frohlich DR (I983) Hybrid sunflower pollination by a manageable composite specialist: the sunflower leafcutter bee 
(Hymenoptera: Megachilidae). Environmental Entomology I2:576-58I

Paschke M, Abs C, Schmid B (2002) Effects of population size and pollen diversity on reproductive success and offspring size in the narrow endemic Cochlearia bavarica (Brassicaceae). American Journal of Botany 89:1250-1259.

Pasquet RS, Peltier A, Hufford MB, Oudin E, Saulnier J, Paul L, Knudsen JT, Herren HR, Gepts P (2008) Long-distance pollen flow assessment through evaluation of pollinator foraging range suggests transgene escape distances. Proceedings of the National Academy of Sciences I05:13456-I346I.

Phillips JK, Klostermeyer EC (1978) Nesting behaviour of Osmia lignaria propinqua Cresson (Hymenoptera: Megachilidae). Journal of the Kansas Entomological Society 5I:9I-I08.

Rasmussen IR, Brodsgaard B (1992) Gene flow inferred from seed dispersal and pollinator behaviour compared to DNA analysis of restriction site variation in a patchy population of Lotus corniculatus L. Oecologia 89:277-283.

Rieger MA, Lamond M, Preston C, Powles SB, Roush RT (2002) Pollen-mediated movement of herbicide resistance between commercial canola fields. Science 296:2386-2388.

Schulke B, Waser NM (200I) Long-distance pollinator flights and pollen dispersal between populations of Delphinium nuttallianum. Oecologia 127:239-245.

Seeley TD (1995) The wisdom of the hive. Harvard Univ. Press, Cambridge, MA.

St.Armand PC, Skinner DZ, Peaden RN (2000) Risk of alfalfa transgene dissemination and scale-dependent effects. Theoretical and Applied Genetics I0I:I07-II4.

Tepedino VJ, Sipes SD, Griswold TL (1999) The reproductive biology and effective pollinators of the endangered beardtongue Penstemon penlandii (Scrophulariaceae). Plant Systematics and Evolution 219:39-54.

Thomson JD (1986) Pollen transport and deposition by bumble bees in Erythronium: influences of floral nectar and bee grooming. Journal of Ecology 74:329-34I.

Thomson JD, Price MV, Waser NM, Stratton DA (1986) Comparative studies of pollen and fluorescent dye transport by bumble bees visiting Erythronium grandiflorum. Oecologia 69:56I-566.
Thomson JD, Thomson BA (1989) Dispersal of Erythronium grandiflorum pollen by bumblebees: implications for gene flow and reproductive success. Evolution 43:657-66I.

Torchio PF (1989) In-nest biologies and development of immature stages of three Osmia species (Hymenoptera: Megachilidae) Annals of the Entomological Society of America 82:599-6I5.

Van Deynze AE, Fitzpatrick SM, Hammon B, McCaslin MH, Putnam DH, Teuber LR, Undersander DJ (2008) Gene flow in alfalfa: biology, mitigation, and potential impact on production. Council for Agricultural Science and Technology Special Publ. no. 28, Ames, Iowa .

Van Deynze AE, Sundstrom FJ, Bradford KJ (2005) Pollenmediated gene flow in California cotton depends on pollinator activity. Crop Science 45:1565-I570.

von Frisch K (1967) The Dance Language and Orientation of Bees. Harvard Univ. Press, Cambridge.

Waddington KD (1979) Flight patterns of three species of sweat bees (Halictidae) foraging at Convolvulus arvensis. Journal of the Kansas Entomological Society 52:75I-758.

Ward M, Dick CW, Gribel R, Lowe AJ (2005) To self, or not to self... A review of outcrossing and pollen-mediated gene flow in neotropical trees. Heredity 95:246-254.

Waser NM (1982) A comparison of distances flown by different visitors to flowers of the same species. Oecologia 55:25I-257.

Waser NM (1988) Comparative pollen and dye transfer by pollinators of Delphinium nelsoniit. Functional Ecology 2:4I-48.

Woodgate JL, Makinson JC, Lim KS, Reynolds AM, Chittka L (2016) Life-long radar tracking of bumblebees. Plos One I I:e0I60333.

Zurbuchen A, Cheesman S, Klaiber J, Müller A, Hein S, Dorn S (2010a) Long foraging distances impose high costs on offspring production in solitary bees. Journal of Animal Ecology 79:674681.

Zurbuchen A, Landert L, Klaiber J, Müller A, Hein S, Dorn S (2010b) Maximum foraging ranges in solitary bees: only few individuals have the capability to cover long foraging distances. Biological Conservation I43:669-676. 